\title{
Code-Switching Pedagogies and African American Student Voices: Acceptance and Resistance
}

\section{Teachers should provide}

nonthreatening spaces for

negotiating and applying

nonstandard and Standard

English and recognize that

home language is linked to

student identity.
K. Dara Hill

A $\mathrm{n}$ ongoing phenomenon in the affluent Oak Valley School District [all names are pseudonyms] is the situation of working class African American students who cross the boundary from Detroit in the quest for educational parity. The desire for African American families to enroll their children is not necessarily based on the desire to integrate, but on awareness that resources follow the suburbs (Irvine, 1990). The transition is not easy, for in spite of derogatory messages conveyed about Detroit public schools, many transfer students are disconnected from the friends and communities they left behind. They are no longer minority majority students. Instead of being surrounded by peers and teachers who likely understand their speech patterns and cultural norms, they are more likely misunderstood and mislabeled.

Kiki and Monet were African American focal students in Mr. Lehrer's seventh-grade classroom during the 2004-2005 school year. They began their schooling in Detroit but transferred to Oak Valley during their upper elementary school years because their parents were dissatisfied with Detroit's schools. Hence, Oak Valley, an affluent suburb, was perceived as providing better educational opportunities than its urban neighbor, similar to Wells and Crain's (1997) notion of African Americans who perceive that better educational offerings are in the suburbs. However, many teachers at Barrington Middle School were unprepared to effectively teach the precipitous influx of African American transfer students and assumed that their language differences correlated to minimal skills and abilities. Students faced teachers who were uncertain about providing access to standard writing conventions in a nonthreatening manner. This was because teacher preparation, historically, has prepared teachers for work in white, middle class settings (CochranSmith, 2000).

Mr. Lehrer was my key informant at Barrington and represents the culturally responsive teachers in the district. I was referred to Mr. Lehrer by a colleague who taught at Barrington. She expressed concerns about significant demographic changes and subsequent teacher discomfort. However, she professed that he viewed changing demography as an opportunity to tap into 
students' cultural and linguistic resources and employ what Ladson-Billings (1995) termed culturally relevant teaching.

Mr. Lehrer's classroom was an equitable space for all of his students to recognize that everyone speaks a deviation from Standard English. He acknowledged their voices in their writing. At the same time, students used their home language as a scaffold to standard school literacy, recommended by experts in the field (Adger, Christian, \& Taylor, 1999; Bakhtin, 1986; Delpit \& Dowdy, 2002; Wheeler \& Swords, 2006), in a manner that Delpit (1995) and Delpit and Dowdy (2002) would term nonthreatening.

\section{Purpose}

In this study, I examine how Mr. Lehrer developed a respect for diversity in language use. Because Monet and Kiki actively voiced pride and confidence in their identity and use of African American Vernacular English (AAVE), this article chronicles their voices and writing as they acknowledged distinctions between home and school literacies. Mr. Lehrer's use of students' home languages to explore their unofficial world while providing access to Standard English is examined. Nonstandard writing conventions through Mr. Lehrer's enactment of poetry writing, informal literature responses, and writer's notebook, are demonstrated. Standard writing conventions are illustrated through a letter to future self, formal literature response, and district writing assessment.

\section{AAVE}

AAVE can be differentiated from other dialects of English. Therefore, its systematic grammatical and phonological features define AAVE as a variety of the English language (Rickford \& Rickford, 2000). An example of a grammatical feature includes dropping the third-person singular $s$, as in she do for she does. Another grammatical feature includes the zero cupola, or absence of is or are. Phonological features include $r$-lessness, such as stow for store and the absence of -g, as in goin' for going (Rickford \& Rickford, 2000, p. 151). To that end, Rickford and Rickford contended that AAVE is a systematic and rule-governed language. AAVE is recognized as the "primary language of African American students,” (Rickford, 1999, p. 1) which should be taken into account in "facilitating mastery of English language skills" (p. 1). Rickford and Rickford (2000) claimed that AAVE features can be detected in the speech patterns of working class speakers in urban areas. Moreover, many speakers of AAVE do not employ its features all the time, nor do all African Americans speak AAVE. AAVE speakers are typically made to feel that they are the only ones who speak a deviation from Standard English (Wolfram, 1999).

\section{Code-Switching Pedagogies}

Code-switching pedagogies call for employing students' home language to facilitate appropriate nonstandard and standard contexts for writing and speaking (Adger et al., 1999; Bakhtin, 1986; Delpit \& Dowdy, 2002; Wheeler \& Swords, 2006). Traditionally, teachers have regarded Standard English as correct while nonstandard features are deemed as errors that warrant correction. Carrie Secret, a noted teacher in Oakland, California, maintained a corrective approach until recognizing that students were more responsive upon being encouraged to translate the structure of AAVE in a first draft to Standard English for the final draft (Miner, 1997). Rather than regard AAVE features as incorrect, code-switching pedagogies require that teachers make a transition from the paradigm of correction to helping students use language patterns for appropriate settings (Baker, 2002; Wheeler \& Swords, 2006). Teachers must be knowledgeable of AAVE features (Delpit, 1997) to model corresponding rule-governed aspects of AAVE and Standard English (Baker, 2002; Wheeler \& Swords, 2006).

To illustrate, Wheeler and Swords (2006) pointed out the rule, owner + owned $=$ possession, a rulegoverned aspect of AAVE. In Standard English, the corresponding rule is owner's + owned $=$ possession. The AAVE feature friend house, for instance, corresponds with the Standard English feature friend's house. Rather than assume that students do not understand possession, teachers must juxtapose grammatical differences side by side and help students determine the appropriate context for use (Wheeler \& Swords, 2006). When writing a nonstandard narrative, for example, friend house would be acceptable. Friend's house would be appropriate for a formal essay or standardized test. 


\section{Resistance is}

embedded in sensing

their identity and

home language have

been compromised,

as a result of

code switching to

standard word

choices that do not

accurately depict

how they speak.
Code-switching pedagogies align with standards devised by the International Reading Association and National Council of Teachers of English (1996) and embed developing an understanding of, and respect for, diversity in language use, patterns, and dialects. Teachers in Michigan are required to implement standards from Grade Level Content Expectations (www.mich. gov) to inform instructional decisions. Nonstandard conventions are embedded in appropriating voice and a personal style by exhibiting individuality to enhance the written message.

In contrast, local and national standards posit that standard writing conventions embody standard grammar and usage. Fecho, Davis, and Moore's (2006) work with African American adolescents prompted researchers to question traditional grammar practices that were threatening in nature, because of conflicts surrounding what they knew about students' lives and perceptions that their use of AAVE was regarded as wrong. Researchers determined that explicit grammar instruction yielded minimal results, which prompted them to facilitate student analysis of mainstream and AAVE language features in a nonthreatening manner. Similarly, Baker (2002), a high school English teacher, prompted her students to study the features of how they speak with family and friends. Eventually, students became fascinated with what she terms triangulation, in which they compared home language features with academic and professional English.

\section{Writers' Workshop}

The workshop approach provides opportunities to enact the writing process, in which students participate in prewriting and drafting (Atwell \& Newkirk, 1987; Calkins, 1994). Teacher and peer conferring supports students toward standard conventions in a final draft. Students are provided a scaffold from nonstandard to standard conventions of writing and speaking and supported in distinguishing between corresponding nonstandard and Standard English features (Baker, 2002; Wheeler \& Swords, 2006).
In spite of teachers' intentions to provide codeswitching pedagogies within the frame of the workshop approach, Fecho et al. (2006) revealed the potential for students to resist switching to the culture of power for any reason. Resistance is embedded in sensing their identity and home language have been compromised, as a result of code switching to standard word choices that do not accurately depict how they speak.

\section{Methodology}

Findings in this article are grounded in integrated and excerpt style (Emerson, Fretz, \& Shaw, 1995). Data reduction was guided by salient themes that emerged through interpretation of units of analysis. Integrated units of analysis include in-the-moment field notes and student writing samples. Excerpted units of analysis include transcribed teacher and student interviews.

\section{Research Site and Participants}

Data were based on observations in a seventh-grade English classroom at Barrington Middle School in an affluent Detroit suburb. The class enrolled 29 students. Twenty-one students were European American, 5 were African American, 1 was Asian American, 1 was French, and 1 was Ethiopian. There were 15 girls and 14 boys. The participants were the most racially and ethnically diverse class of Mr. Lehrer's career. At the same time, the composition corresponded with a typical classroom at Barrington. I selected Monet and Kiki as focal students because they represented Detroit students entering Oak Valley for educational parity. In addition, they were selected because they desired to preserve their Detroit identity and were vocal about preserving their voices in their writing.

\section{Data Collection and Analysis}

The class was observed during one 46-minute period, three to five days per week over a five-month period from February to June 2005. The findings revealed in this article are situated in a broader dissertation and ethnographic case study, which emphasized the nature of literature-based instruction and writing practices in Mr. Lehrer's classroom. For the purpose of this article, data were gathered in an effort to demonstrate 
the nature of writing pedagogy that was conducive to code-switching pedagogies. Therefore, I focused on data which drew from Monet and Kiki's home language to support standard and nonstandard writing conventions.

From my field note analysis, I devised assertions that were guided by Mr. Lehrer's instructional decisions during the writing process. In addition, I paid attention to the manner in which Kiki and Monet responded to those decisions.

Teacher interview excerpts were analyzed and coded into theoretical memos. Salient themes were devised and coded into assertions. I made decisions about assertions and data reduction based on Mr. Lehrer's attentiveness to distinguishing between standard and nonstandard writing conventions and attention to language varieties. Student interview excerpts rendered salient themes that were coded into assertions. While analyzing interview data, I sought to identify what I perceived to be compelling responses regarding distinguishing between standard and nonstandard writing conventions.

Monet and Kiki's written artifacts were integrated to support assertions. Data reduction was determined by writing, which illustrated distinctions and transitions between standard and nonstandard writing conventions. To account for emic perspectives, writing conventions were interpreted in relation to corresponding rule-governed language features. Reference to and analysis of student writing samples that illustrate AAVE features, along with individual style and voice, are termed nonstandard. Integrated writing samples include illustrations of how Mr. Lehrer might have corrected, had he called for standard conventions. In addition, writing samples that focus on standard grammatical usage in the context of seventhgrade expectations are termed standard.

I approached the data with the following research questions: What is the nature of writing practices that facilitate standard and nonstandard writing conventions? How are these opportunities linked to student identity? How do focal students respond to these opportunities?

\section{Nonstandard Writing Conventions}

To establish a foundation for valuing nonstandard writing conventions, Mr. Lehrer reported in the following interview excerpt that he began the school year by reading aloud Nightjohn (Paulsen, 1993) to approve the notion of voice in the African American linguistic tradition and accurately depict the way a character speaks:

Mr. Lehrer: It comes from literature, in Nightjohn, the narrator Sarny has an uneducated way of telling the story with her terms. Right away they notice that and obviously I'm standing up there reading that and that must be some sort of stamp of approval.

Author: Right. You do give a stamp of approval, don't you?

Mr. Lehrer: You know, if you're a language artist, which is to say writer, you use languages in a natural way of conveying the way someone would speak.

Therefore, the stamp of approval and notion of language artist suggests that he sustained a comfort level for students to use nonstandard contexts for writing. Delineating features from literature provided a space for students to determine authentic use of voice, in a manner similar to Fecho et al. (2006) who facilitated critical analysis of AAVE features in literature with students.

During the onset of the study, students appropriated nonstandard conventions during poetry writing practices. According to integrated field notes, Mr. Lehrer modeled and listed actions that could become poems inspired by Atwell (2002), including playing sports, styling hair, and playing music. He directed students to devise lists as a foundation for their own poem. Kiki's list included a death in the family and Monet's included a surprise party.

After designated time to construct lists, Mr. Lehrer displayed and read aloud poems written by students from Atwell's (2002) work and discussed features to model free-verse poetry. His students were attentive to word choices that conveyed personal experiences and voice. 
Kiki employed nonstandard conventions to express sadness surrounding her cousin who died (see Figure 1):

We were close friends also cousins did everything for one another...But now I got to live and make it somehow...I know I got to move on....

Kiki spoke strongly about preserving her voice in her writing, which is intimately connected with her family. Such writing opportunities allowed her to build on her cultural and linguistic strengths. Her use of "I got" illustrates the deletion of the word have, which Rickford and Rickford (2000) noted is a grammatical feature of AAVE. Her description of being friends and cousins has a rhythmic quality that displays her social world and fondness for rap music. Requiring standard conventions would have rendered

Figure 1 Kiki's Poem in Nonstandard Conventions

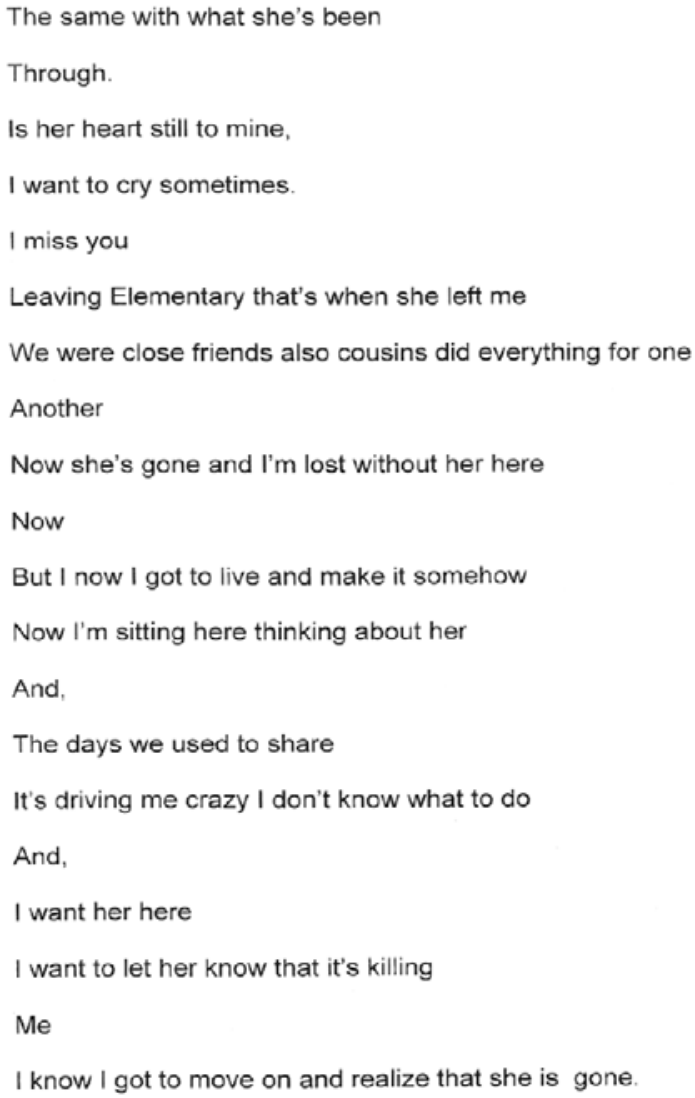

the absence of Kiki's voice: "We were close friends and cousins and did everything for each other. Now I have got to live and make it somehow. I know I have got to move on...."

The following excerpts in Monet's poem about a surprise party for her uncle illustrate a strong sense of voice (see Figure 2):

My uncle says "Where the kids at." She says "They busy."... She says "Whateva, but how did you do at the casino?

The examples that represent her relatives speaking naturally provide an accurate depiction of how they would speak. To write their voices in Standard English is an inaccurate depiction and diminishes who they are. Monet's appropriation of voices in her family is an example of acknowledging strength in cultural linguistic tradition. A phonological AAVE feature can be detected in the presence of $r$-lessness (Rickford \& Rickford, 2000), upon writing "whateva." In

\section{Figure 2 Monet's Poem in Nonstandard Conventions}

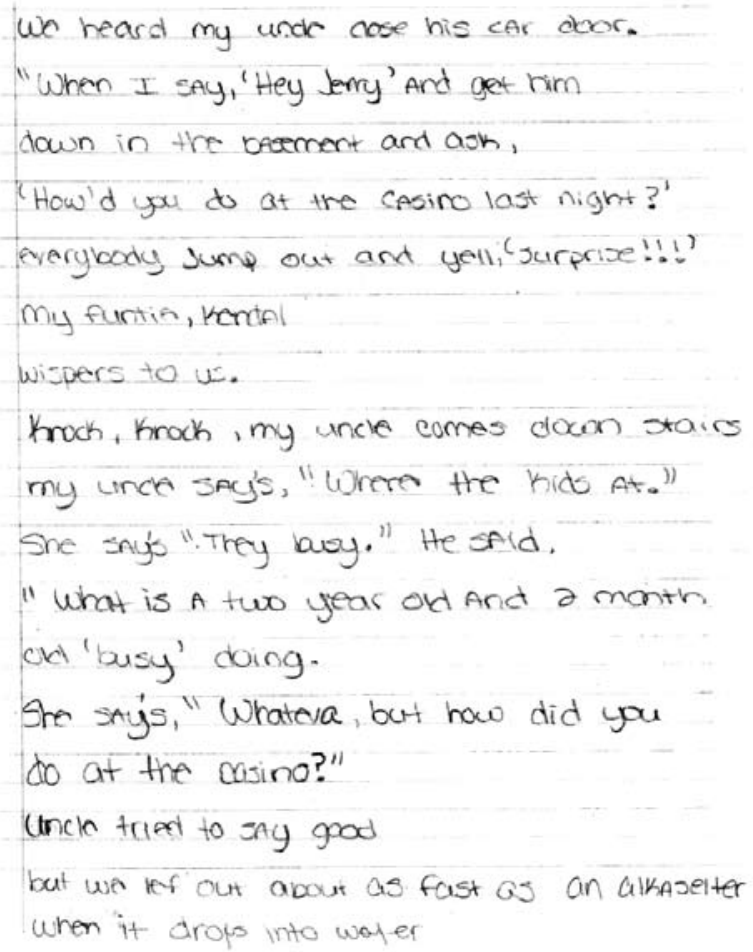


addition, a grammatical AAVE feature of the zero $\mathrm{cu}-$ pola includes the absence of the verb are (Rickford \& Rickford, 2000) upon writing "they busy." If standard conventions were required, it would have read, "My uncle says, 'Where are the kids?' My aunt says, 'They are busy.' She says, 'Whatever, but how did you do at the casino?"”

Students also employed nonstandard conventions during informal literature-based writing responses. Particularly salient were informal jottings about multicultural text set novels they were reading surrounding the theme prejudice. Monet identified prejudice in Dragonwings (Yep, 1981), in which written ideas were influenced by her peer-led discussion group (see Figure 3):

The Chinese thought the white was bad and Moon Shadow Lee has killed people...Whites were mean to the Chinese and thought they were weird.

Because the assignment emphasized ideas conveyed by Monet's discussion group and not explicitly grammar, Monet's writing illustrates standard and nonstandard use of was/were. However, her use of AAVE features was not as prevalent as in her poem that invited her voice. A grammatical AAVE feature is detected in her use of "white was" (Rickford \& Rickford, 2000). For a standard context, she would have jotted "whites were."

Writer's notebook was a daily enactment where students were required to write a half page daily. Students wrote about self-selected topics surrounding their daily experiences and social worlds. Integrated writing samples were not included in this article because Mr. Lehrer collected notebooks periodically and redistributed them very quickly, to ensure continued daily writing. However, the enactment is necessary to note, to illustrate an ongoing use of nonstandard writing conventions. Ongoing practice and integrated writing samples correspond with local and national standards to appropriate voice and style.

Monet and Kiki affirmed their awareness of writing nonstandard conventions during an interview:

Author: Monet, when you asked Mr. Lehrer if you could use your voice, he said of course you can, without being marked down.

Figure 3 Monet's Informal Literature-Based Writing Response

\section{BIG QUESTIONS ABOUT THE BOOK}

- PREJUDICE: How is prejudice part of the story?

o Gather examples from the story:

- Who is showing prejudice and towards whom? arid $r$.

- How is that prejudice wrong and not constructive?

Pregudice is a part of my story in many ways some ways are the chinese thought Shadow hee nas killad perole ard Chinese people Say white hurt them. whites were mor to chinese and thought they were wierd. 
Monet: Because I did spell words how I would say 'em, and, like aight (alright),

Kiki: Y'all!

Monet: Stuff like that, and y'all, because we don't talk like, yeah, you guys are, we don't talk like that, so it's just how I was raised and where I came from, they talk like that.

Kiki: It's not basically street talk.

Monet: It's how we were raised.

Author: And that's very important, that Mr. Lehrer sees that as important too, because that's your voice. If you read Maya Angelou, or even Mildred Taylor, there's so much of that rich language, even Joyce Hansen. It's really an important technique of writing.

Monet: Because he said it was important to write about us, and it would have been hard to write about me talking in someone else's voice.

My initial question to Monet was prompted by my observation during class when she asked Mr. Lehrer if she would be marked down for using her voice during a nonstandard writing opportunity. Given Mr. Lehrer's ongoing acceptance of students employing their voices, it appears odd that she would ask such a question. However, considering the broader context of schooling that is typically not accepting of language varieties, Monet's question makes sense.

The following excerpt illustrates Kiki's voice, who exhibited contradictory emotions of not wanting to change her manner of speaking to fit in, but desired to be accepted by her peers:

Kiki: I've been going through a lot of ups and downs because people here say that oh my god, look at how ghetto she is.

Author: To you? Or you hear them saying it about you?

Kiki: It really doesn't matter, because like, I said, this is me. This year I started to fit in more with the white people because I start talking, like whew, and they start to say some of the stuff I say, like you would hear them say it, and it made me feel good, looking at them, that they might say like the words I use. Last year I was just so into getting into everybody but this year I think like who I want to be.

In this interview excerpt, Kiki voiced the importance of preserving her identity through her home language among her peers at Barrington. She spoke AAVE and was referring to her counterparts who spoke European American Vernacular English. Although both forms are deviations from Standard English, Kiki's reality was that the language she brought to school, as has been historically constructed by the dominant culture, was perceived by many of her teachers and peers as deficient.

Interview excerpts reveal that Monet and Kiki were openly aware of the distinctions between standard and nonstandard conventions of writing and speaking, along with the perception of their home language as street talk in the dominant culture and in school. Both girls grappled with their identity and knew that standard writing conventions were skills they needed. Similar to adolescents cited by Fecho et al. (2006) it meant accepting or rejecting Standard English and compromising their identity upon switching writing conventions to the culture of power.

\section{Standard Writing Conventions}

To facilitate standard conventions, Mr. Lehrer maintained an expectation of what he called the "errorless draft," which required students to respond to his written feedback in their final draft and to resubmit the attached rough draft so that he could detect that students responded to feedback. The expectation for writing standard conventions and appropriating skills in meaningful contexts reifies Delpit's (1995) assertion that intervention is needed to write in standard contexts. Scaffolding from students' home language to inform standard writing was an enactment of codeswitching pedagogies (Baker, 2002; Bakhtin, 1986; Delpit, 1995; Wheeler \& Swords, 2006). Whenever possible, he interacted with students to clarify feedback. Therefore, he actively sustained awareness of standard writing and skills in meaningful contexts, aligned with grammar and usage embedded in local and national standards. 
During a formal interview, Mr. Lehrer acknowledged the importance of sustaining skills in meaningful contexts, as an integral facet of standard acquisition and usage:

Mr. Lehrer: Yeah, sure, because that's the basis of the class. I mean, really, this kind of class revolves around the idea that those skills exist...within the context of important language usage. So if you're using language in an important way, which is to say you're using it to express meaning.

Author: True, so, you put skills in meaningful contexts, not finding the subject and the predicate.

Mr. Lehrer: Even though occasionally I will do that if I really want to mention some things that they don't have, I think it's such a vacuum.

Author: So that would make you a little less approachable.

Mr. Lehrer: I think so, I think they know as the year goes on that I care about that stuff a lot. I really do. I demonstrate that when I get their papers and mark them up and when I talk to them about their writing, but it would have to be in a meaningful context.

This excerpt reveals that Mr. Lehrer's written comments were intended to provide skills in meaningful, nonthreatening contexts. He considered ongoing written feedback an impetus to talk to students about their writing in an effort for them to acquire standard conventions. Mr. Lehrer determined his enactment of providing skills instruction and linking Standard English with home language in the context of their writing was more effective than isolated grammar worksheets. In addition, he was more approachable to his students.

Providing written feedback for 137 students across all of Mr. Lehrer's class sections was time consuming and posed constraints for meeting each student personally to address his comments. However, each student was provided with at least written feedback and opportunities to confer with a peer. He expected them to assume responsibility and respond to written feedback until the draft was errorless.

The "Letter to Future Self" was a writing assignment that employed standard writing conventions. Students wrote a letter to their senior self graduating from high school. Student letters would be mailed to them near the end of their senior year of high school.

The guidelines dictated the letter genre. Each paragraph manifested topics that were appropriate to the student during their seventh-grade year, including physical appearance, things that have happened this school year, and hopes and dreams for the future. Rough drafts included Mr. Lehrer's feedback for students to apply to the final edited version.

Kiki wrote about her physical appearance (see Figure 4):

Normally you see me wearing jeans, button-ups, skirts, and a lot of t-shirts. My hair is like a silky black with a tint of brown.

Mr. Lehrer's feedback did not embody scaffolding toward Standard English, indicating Kiki's awareness of writing standard conventions for a standard context. In contrast with her poem, no AAVE features are detected in this sample. Comments indicated spelling clarification and including more detail in another

\section{Figure 4 Kiki's Letter to Future Self}

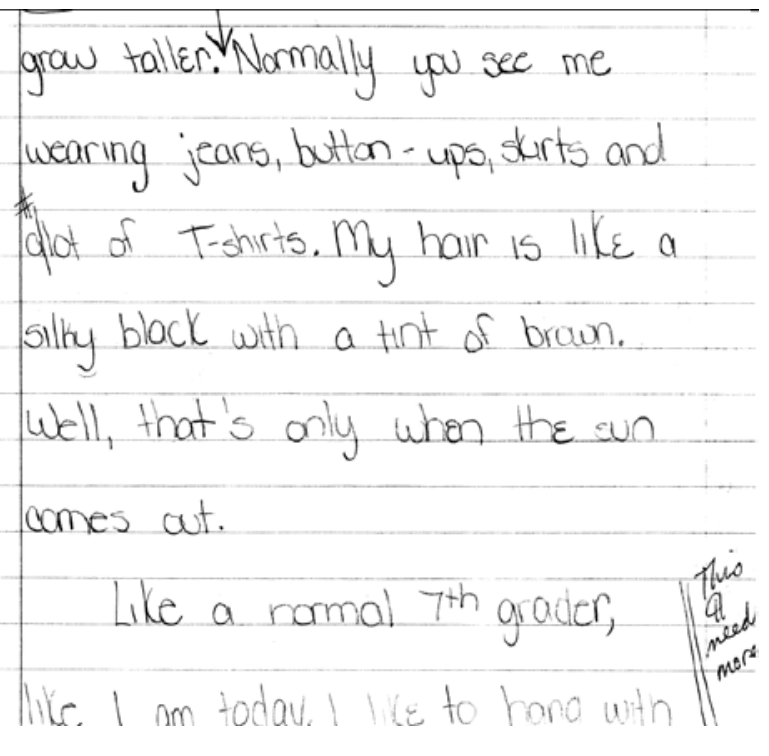


paragraph. Kiki appropriated standard conventions in her writing under the directive to employ them. Her acceptance of Standard English is significant because she resisted Mr. Lehrer's feedback earlier in the study.

To illustrate, one month prior, Kiki was confrontational about preserving her nonstandard conventions in a formal essay paying tribute to her mother, similar to resistant students cited by Fecho et al. (2006). During that time, she was extremely vocal upon questioning Mr. Lehrer about his written feedback. According to integrated field notes, he suggested she write "My mother has taken care of me" instead of "My mother have taken care of me." Her use of "have" corresponds with what Rickford and Rickford (2000) suggested is a grammatical feature of AAVE. She reasoned that her voice would be compromised if she changed the wording. According to field note jottings, she bellowed,

Mr. Lehrer, this is bold! You put down the way you wanted me to write, not the way I want to write it, in my own words!

Because Mr. Lehrer was conferring with another student, I intervened and informed her that she was writing in a standard context unlike her aforementioned poem. We discussed the importance of distinguishing between standard and nonstandard writing contexts, and that there are contexts where we give up a part of ourselves when we write for school. She seemed to understand more fully when I expressed that I give up a part of myself when I write for academic purposes. Hence, Kiki's letter illustrates that she used standard conventions on her own, which suggests her awareness of distinguishing between appropriate contexts for writing.

To express hopes and dreams for the future, Monet wrote the following (see Figure 5):

My hopes and dreams for the future are to be a famous singer, and if that doesn't work I want to be a pediatrician. When I finish college, I want to make good money and be a very rich person.

Mr. Lehrer noted spelling errors and punctuation to help Monet prepare for her final draft. In contrast with her poem and reading response, Monet's draft does not indicate evidence of AAVE features. This illustrates her awareness of writing standard conventions for a standard context.

Upon completing Dragonwings (Yep, 1981), Monet wrote a final essay about prejudice in her book. The following illustrates her standard use of was and were (see Figure 6):

The Chinese automatically thought that the white people were mean and that's racist. The white people were also racist to the Chinese people because they were mean to them....

Monet's writing reflects her response to $\mathrm{Mr}$. Lehrer's feedback, in which he scaffolded the appropriate conventions for was and were. Her final draft does not indicate evidence of AAVE features. It was intended to be written in Standard English and presents a transition from her informal jottings one month prior.

Students took a district writing exam where they selected from three writing prompts and employed standard conventions. However, its impromptu nature allowed for students' editing marks. They drafted two writing samples and submitted the determined best draft to the district for scoring purposes. Kiki selected "Fitting in," a prompt that was personal in nature (see Figure 7):

\section{Figure 5 Monet's Letter to Future Self}

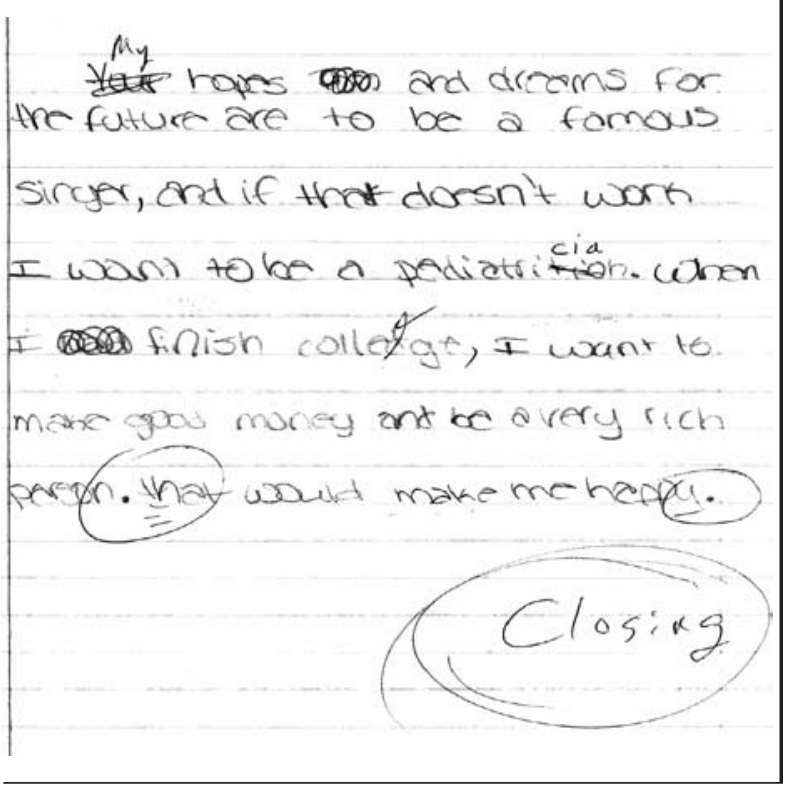




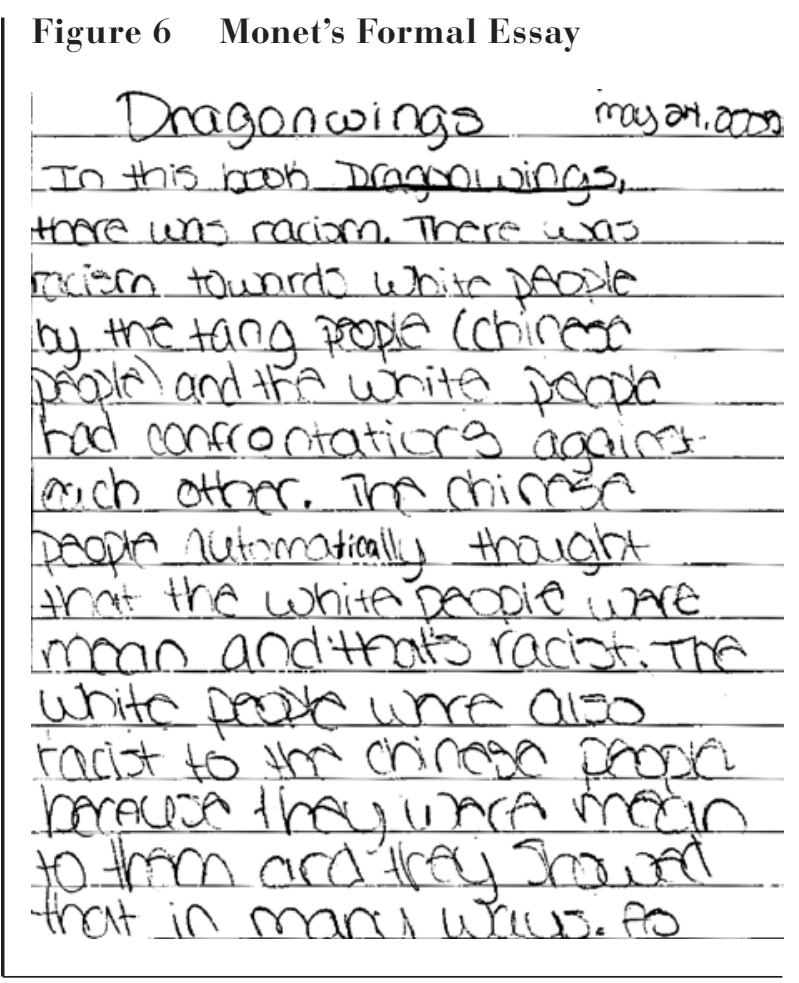

I'm still tryin to fit in with the school because really I'm still a girl from the ghetto.

Mr. Lehrer brought Kiki's writing test to my attention because he sensed that she responded sincerely to the writing prompt. In a formal setting, Kiki selected a topic that coincided with her experiences as an African American student in a suburban context. The majority of this unassisted writing sample indicates Kiki's awareness of standard conventions. For example, $I$ consistently corresponds with I'm, in contrast to her use of $I$ with the absence of have from her poem. However, her use of "tryin to fit in...I'm still a girl from the ghetto" presents an example of resisting the dominant discourse. She attempted to preserve a semblance of her voice in a context where preserving her sense of self compromised fitting in, a manner of resisting switching to the culture of power for any reason (Fecho et al., 2006). Tryin illustrates the absence of $-g$, a phonological AAVE feature (Rickford \& Rickford, 2000).

Although Mr. Lehrer regarded Kiki's writing as a strong depiction of her experience, he submitted her other writing sample upon deciding it was more

\author{
Figure 7 Kiki's District Writing Exam \\ I'm still tryin to fit in with \\ the school \\ Because really l'm still a \\ girl from the ghetto. The \\ struggle and hâtimes. I don't \\ know if 1 will be fine. But \\ I dont core what people sal \\ because this is me. my \\ mother, sister and brother \\ changed when we moved \\ out here. But in still the \\ some.
}

appropriate for outside readers. Therefore, Kiki's writing was acceptable to Mr. Lehrer, but for formal testing he sensed that her word choices, particularly ghetto, might displease the readers. He further reasoned the other draft would earn a higher score. Emically, standard language usage was acceptable for standardized testing purposes.

During an interview, Kiki and Monet described their awareness of writing Standard English and compromising their voice:

Author: So when you're in a classroom and when you're writing you know how to write formal and...

Monet: Right, I write formal.

Kiki: But it's different for me because when we moved over here my mother, my sister, my brother they were all changed, but it's hard for me.

Monet: I didn't change at all.

Kiki: Like my whole family changed when we moved over here. 
Monet: I won't change my way of speaking. I would use better words, but I wouldn't try to change.

This excerpt illustrates not wanting to change who they were or how they spoke for anyone, similar to adolescents cited by Fecho et al. (2006), who resisted the culture of power for any reason. At the same time, they were aware of standard writing contexts in school. As former Detroit residents, they were deeply connected with their Detroit identity. They wanted to be understood and preserve their voices, not only for speaking purposes but also in writing for school contexts. However, writing samples and integrated field notes indicate that Kiki was more resistant to the culture of power than Monet, who was more accepting of code switching for appropriate contexts.

\section{Conclusion}

Mr. Lehrer facilitated a classroom community that nurtured students' awareness of language varieties from the onset of the school year. The ongoing use of code-switching pedagogies presented access to Standard English. Because they were presented with the same writing and revision opportunities, all students gained access to the dominant discourse, not just the African American students from Detroit. They drew from their home language to inform their voices in nonstandard writing contexts, and in some instances they negotiated their voices in standard contexts. Monet and Kiki represented Detroit students who wrote successfully upon accessing their literate identity and culture of the home. At the same time, they were aware of standard writing contexts that required them to compromise themselves. Monet and Kiki were aware that different language forms were appropriate in different contexts.

Mr. Lehrer provided feedback to scaffold from home language to standard writing conventions within the frame of the workshop approach. Monet was responsive to feedback, but there were instances in which Kiki resisted compromising her voice. He simultaneously provided low-stakes opportunities to write in nonstandard contexts. Monet and Kiki's writing and interview excerpts illustrate their com- fort level to write nonstandard conventions to convey their voices.

This occurred in a climate of uncertainty surrounding an unexpected influx of Detroit students. Mr. Lehrer's practices were enacted by few teachers, but his pedagogical decisions were embedded in state and national curriculum standards. Data suggest that students were empowered upon preserving their voice without the threat of correction while also employing home language as a foundation for standard conventions. Current conditions in the overall context of schooling minimize the linguistic aptitude students bring to the classroom.

\section{Final Thoughts and Instructional Recommendations}

The case of Mr. Lehrer presents an example of teaching emically at the local level in everyday practice within a larger structure that resists change (Erickson, 1986). For teachers in everyday practice, the following are recommendations for AAVE speakers and speakers of other varieties of English:

- Never tell students that home language features are wrong and Standard English features are right.

- Balance nonstandard and standard contexts for writing. Teachers must facilitate distinctions and support students as they negotiate appropriate contexts for employing language features.

- Inform student that everyone speaks nonstandard English. Delpit (1997) recommended exploring additional forms of English to compare and contrast varying ways and contexts in which people speak, including characters from different cultural groups on television or in literature.

- Instill motivation by exploring varying ways students express common ideas before emphasizing grammar rules (Baker, 2002). Once students are interested, teachers should make the transition to corresponding rules for academic and professional contexts.

- Provide written feedback during standard writing contexts and confer with students to scaffold from home language to Standard English 
features. Require students to submit the final draft with the initial draft to document changes.

- Model corresponding grammar features in home language and Standard English (Wheeler \& Swords, 2006). Although not demonstrated by Mr. Lehrer, because of his preference to address conventions in the context of actual writing, this strategy supports applying rule-governed features to appropriate contexts. Code-Switching: Teaching Standard English in Urban Classrooms (Wheeler \& Swords, 2006) is a unique teacher resource that illustrates corresponding AAVE and Standard English features. Although intended for elementary grades, the resource is applicable to middle school.

Ultimately, teachers must provide nonthreatening spaces for negotiating and applying nonstandard and Standard English and recognize that home language is linked to student identity (Delpit, 1995, 1997; Fecho et al., 2006). Standard English should be a choice, not an imposition (Baker, 2002). Teachers are responsible for providing awareness of language features and students will inevitably decide what they want to say in standard and nonstandard contexts.

\section{References}

Adger, C.T., Christian, D., \& Taylor, O. (1999). Making the connection. Language and academic achievement among African-American students. Washington, DC: Center for Applied Linguistics.

Atwell, N. (2002). Lessons that change writers. Portsmouth, NH: Heinemann.

Atwell, N., \& Newkirk, T. (1987). Understanding writing: Ways of observing, learning, and teaching (2nd ed.). Portsmouth, NH: Heinemann.

Baker, J. (2002). Triangualism. In L.D. Delpit \& J.K. Dowdy (Eds.), The skin that we speak. Thoughts and language and culture in the classroom (pp. 49-62). New York: The New Press.

Bakhtin, M. (1986). Speech genres and other late essays. Austin: University of Texas Press.

Calkins, L.M. (1994). The art of teaching writing (New ed.). Portsmouth, NH: Heinemann.

Cochran-Smith, M. (2000). Blind vision: Unlearning racism in teacher education. Harvard Educational Review, 70(2), 157-190.

Delpit, L.D. (1995). Other people's children: Cultural conflict in the classroom. New York: The New Press.

Delpit, L.D. (1997). Ebonics and culturally responsive instruction. Rethinking Schools Online, 12(1). Retrieved June 1, 2008, from www.rethinkingschools.org/archive/12_01/ebdelpit .shtml
Delpit, L.D., \& Dowdy, J.K. (2002). The skin that we speak: Thoughts on language and culture in the classroom. New York: The New Press.

Emerson, R.M., Fretz, R.I., \& Shaw, L.L. (1995). Writing ethnographic fieldnotes. Chicago: The University of Chicago Press.

Erickson, F. (1986). Teacher's practical ways of seeing and making sense. East Lansing: Institute for Research on Teaching, Michigan State University.

Fecho, B., Davis, B., \& Moore, R. (2006). Exploring race, language, and culture in critical literacy classrooms. In D.E. Alvermann, K.A. Hinchman, D.W. Moore, S.F. Phelps, \& D.R. Waff (Eds.), Reconceptualizing the literacies in adolescents' lives (2nd ed., pp. 187-204). Mahwah, NJ: Erlbaum.

International Reading Association \& National Council of Teachers of English. (1996). Standards for the English language arts. Newark, DE; Urbana, IL: Authors.

Irvine, J.J. (1990, April). Black parents' perceptions of their children's desegregated school experiences. Paper presented at the annual meeting of the American Educational Research Association, Boston, MA.

Ladson-Billings, G. (1995). Toward a theory of culturally relevant pedagogy. American Educational Research Journal, 32(3), 465-491.

Miner, B. (1997). Embracing Ebonics and teaching Standard English: An interview with Oakland teacher Carrie Secret. Rethinking Schools Online, 12(1). Retrieved June 1, 2008, from www.rethinkingschools.org/archive/12_01/ebsecret.shtml

Rickford, J.R. (1999). Language diversity and academic achievement in the education of African American students-An overview of the issues. In C.T. Adger, D. Christian, \& O. Taylor (Eds.), Making the connection: Language and academic achievement among African American students (pp. 1-30). Washington, DC: Center for Applied Linguistics.

Rickford, J.R., \& Rickford, R.J. (2000). Spoken soul: The story of black English. New York: Wiley.

Wells, A.S., \& Crain, R.L. (1997). Stepping over the color line. African-American students in white suburban schools. New Haven, CT: Yale University Press.

Wheeler, R.S., \& Swords, R. (2006). Code-switching: Teaching Standard English in urban classrooms. Urbana, IL: National Council of Teachers of English.

Wolfram, W. (1999). Repercussions from the Oakland Ebonics controversy-The critical role of dialect awareness programs. In C.T. Adger, D. Christian, \& O. Taylor (Eds.), Making the connection: Language and academic achievement among African American students (pp. 61-80). Washington, DC: Center for Applied Linguistics.

\section{Literature Cited}

Paulsen, G. (1993). Nightjohn. New York: Bantam Doubleday Dell.

Yep, L. (1981). Dragonwings. New York: HarperTrophy.

Hill teaches at the University of Michigan-Dearborn, USA; e-mailkirdara@umd.umich.edu. 